\title{
O IMPACTO DA DOENÇA DE AlZHEIMER NAS RELAÇÕES INTERGERACIONAIS ${ }^{1}$
}

\author{
Deusivania Vieira da Silva Falcão* \\ Júlia Sursis Nobre Ferro Bucher-Maluschke**
}

Resumo

Este estudo investigou, na perspectiva de 24 filhas cuidadoras de seus pais/mães com provável/possível diagnóstico da doença de Alzheimer (DA), o relacionamento entre eles e seus filhos (netos dos portadores). Foram utilizadas uma entrevista com roteiro semiestruturado e o FAST (Family System Test), que analisou a coesão e a hierarquia nas relaçōes. Verificou-se que nas representaçōes atuais das relaçōes intergeracionais a coesão das filhas cuidadoras com seus filhos foi significativamente maior do que a coesão destes com as avós portadoras da DA. Também os netos apresentavam uma maior hierarquia em relação às portadoras da doença nas situaçōes atual e ideal. Concluiu-se que, com a DA, os papéis de avós, de mães e de netos sofreram mudanças que precisaram ser reavaliadas.

Palavras-chave: Alzheimer; cuidadores; avós; relaçôes intergeracionais.

\section{ABSTRACT}

THE IMPACT OF ALZHEIMER'S DISEASE IN INTERGENERATIONAL RELATIONSHIPS

This study investigated, on the perspective of 24 caregiver daughters, caretakers of their fathers/mothers with a probablelpossible diagnosisfor Alzheimer's Disease (AD), the relationship among them and the children of the caregiver (grandchildren of the AD sufferer). The employed tools were an open interview with a semi-structured script, and FAST (Family System Test),

* Professora Doutora da Universidade de São Paulo (USP); Doutora em Psicologia pela Universidade de Brasília (UnB).

** Professora Emérita e Pesquisadora Associada Sênior da Universidade de Brasília (UnB); Professora Titular da Universidade de Fortaleza (Unifor); Doutora em Ciências Familiares e Sexológicas pela Université Catholique de Louvain/Bélgica, com Pós-Doutorado pela Universität Tübingen/Alemanha e pela St. John's University/EUA. 
which analyzed the linking and the hierarchy of the relations. The results pointed that in the current representations of the intergenerational relationship, the linking of the caretaking mother to her children was significantly greater than the linking of these with their AD sufferer grandmothers. It was also verified that the grandchildren showed a higher hierarchy towards the disease's sufferer in the current and ideal family situations. It was concluded that with the onset of $A D$ the roles of grandmothers, mothers and grandchildren suffered changes that needed to be reevaluated.

Keywords: Alzheimer; caregivers; grandparents; intergenerational relationships.

\section{INTRODUÇÃO}

A população de idosos elevou-se significativamente nos últimos anos e uma das principais consequências desse fato, no campo da saúde, foi o aumento da prevalência das demências, sendo a mais comum delas a doença de Alzheimer (DA). Considera-se a DA uma afecção neurodegenerativa progressiva e irreversível de aparecimento insidioso, em que se observam a atrofia cortical difusa, a presença de grande número de placas senis, degeneraçóes grânulo-vasculares, perda neuronal e emaranhados neurofibrilares (Laws, Hone, Gandy \& Martins, 2003). A DA afeta cada pessoa de maneira diferente e atinge homens e mulheres de todas as raças, níveis socioeconômicos, grupos étnicos e lugares geográficos. O impacto da doença, na vida do paciente, está relacionado às suas características pessoais (personalidade, condiçôes físicas, estilo de vida) antes da doença (OMS, 1994). No Brasil, o conceito dessa enfermidade foi difundido aproximadamente na década de 1990, quando profissionais de áreas como Geriatria, Gerontologia, Neurologia e Psiquiatria desenvolveram interesse pelo tema. Não obstante, grande parcela da população ainda desconhece suas características.

Sinaliza-se que à medida que a doença progride são observados, também, sintomas psicóticos transitórios. As perdas cognitivas aumentam invariavelmente, e o sujeito vai perdendo a memória e a autonomia, até permanecer dependente de outros para a execução de tarefas básicas. $\mathrm{O}$ cuidado pode ser executado pelos familiares, por profissionais e por instituições de saúde. $\mathrm{Na}$ família, o papel de cuidador recai especialmente sobre a mulher, preferencialmente a esposa, seguida da filha, ocorrendo casos em que idosos morando com seus filhos casados são cuidados, sobretudo, por suas noras.

Ocorre que a manutenção dos papéis de gênero difundidos pela cultura brasileira retrata o fato de que as mulheres jovens e de meia-idade, além de cuidarem dos filhos, cuidam também dos pais (Goldani, 1999), sendo denominadas 
"cuidadoras sanduíche" (Brody, 1989). O impacto da doença de Alzheimer na vida das cuidadoras dos pacientes reflete sintomas vivenciados por elas, tais como estresse, depressão, tristeza crônica, distúrbios do sono e isolamento, além das dificuldades financeiras e sociais (Mayer, 2001; Sawatzky \& Fowler-Kerry, 2003). Os idosos, por sua vez, residem na casa das filhas, especialmente quando são mais pobres e possuem piores condições de saúde. Desse modo, a convivência e a corresidência de três ou mais geraçôes é uma estratégia familiar que enfrenta desafios e pode ser utilizada para beneficiar tanto as gerações mais novas como as mais velhas. Os conflitos intergeracionais advindos dessas interações, bem como a superação deles, dependerão, dentre outros aspectos, da maior ou menor flexibilidade da família para interagir.

Numa ótica sistêmica, a família pode ser considerada um sistema aberto, devido ao movimento de seus membros dentro e fora da interação de uns com os outros e com os sistemas extrafamiliares, num fluxo constante de informação, energia e material. Assim, os comportamentos e as ações de um dos seus membros tanto influenciam como são influenciados pelos dos outros. O sistema familiar se diferencia e exerce suas funçōes através de subsistemas. Cada membro é um subsistema, ou grupos maiores, que possibilitam a composição de outros subsistemas, por geração, sexo, função ou interesse (Minuchin, 1982).

As fronteiras do subsistema são as regras que definem quem participa e como. Para o funcionamento apropriado da família, elas devem ser nítidas, e isso requer que os pais, os filhos e os netos aceitem o uso diferenciado de autoridade. Esses "diferentes níveis de autoridade" compõem a hierarquia familiar (Minuchin, 1982), também compreendida como "níveis de status e poder" (Haley, 1976). A complexidade relacional é regida através da comunicação, que constitui e caracteriza a interação familiar, a partir da qual são construídas, no tempo, as regras próprias de cada grupo, favorecendo o bom funcionamento do sistema.

Outro aspecto relevante na determinação da saúde do sistema familiar é a coesão. Este termo é geralmente definido como vínculo emocional ou ligação afetiva entre os membros da família (Kelsey-Smith \& Beavers, 1981; Olson, Russel \& Sprenkle, 1983). Segundo Penna (2004), nas famílias coesas os membros referem ter engajamento e envolvimento entre si, proporcionam apoio mútuo, são capazes de compartilhar sentimentos de dor, toleram melhor as emoções negativas e são as que melhor prestam apoio ao parente enfermo. Um aspecto relacionado à alta coesão familiar é a capacidade de adaptação diante de eventos que possam vir a afetar negativamente o sistema. Porém, de acordo com Wood (1985), graus extremos de coesão, sejam em direção à alta ou à baixa coesão, estão associados à disfunção familiar. 
A coesão, a hierarquia e as interações entre os membros podem ser afetadas devido às circunstâncias específicas ocorridas na família, tais como o surgimento e desencadeamento da doença de Alzheimer. Segundo Silveira (2003), existem diversas maneiras de os familiares lidarem com esta doença. Alguns se distanciam para evitar confrontos, redefinição dos papéis estabelecidos, compromissos desagradáveis ou pelo próprio medo de desenvolver a demência. Outrossim, as experiências familiares anteriores à doença interferem nas relações atuais, ora proporcionando bem-estar, ora exacerbando conflitos.

Algumas pesquisas internacionais (Beach, 1994, 1997; Brody, 1989; Creasey \& Jarvis, 1989; Szinovacz, 2003), envolvendo avós com demência, destacaram as relações intergeracionais, ressaltando as mudanças na dinâmica familiar. As pesquisas de Beach $(1994,1997)$ averiguaram a experiência positiva e o impacto na vida dos netos adolescentes cuidadores de avós com Alzheimer. Analisando as relações familiares de portadores de DA, Creasey e Jarvis (1989) verificaram que o fardo vivenciado pelas filhas cuidadoras afetava a relação com seus filhos e o relacionamento destes com os avós portadores.

Szinovacz (2003), por sua vez, baseando-se na perspectiva sistêmica, investigou as mudanças na dinâmica familiar e no relacionamento pais-filhos adolescentes, quando um dos avós era portador de demência e morava junto com a família. Através das entrevistas com 17 adolescentes, Szinovacz (2003) constatou que a situação de cuidado afetava o relacionamento familiar de maneira positiva e negativa e que os netos lamentavam as restrições que tinham, em decorrência de a família se voltar unicamente para os cuidados com os avós. Por outro lado, os adolescentes revelaram considerável respeito e empatia por seus pais que eram cuidadores primários e retrataram que o envolvimento que eles mesmos tinham, nas atividades de cuidados para com os avós, aumentou os laços de amizade com seus pais. Similarmente, Brody (1989) sinalizou que os netos podem ajudar os seus avós com Alzheimer participando diretamente dos cuidados, envolvendo-se afetivamente com eles e fortalecendo laços intergeracionais. Todavia, um dos impactos negativos na vida dos netos cuidadores é a vivência de limitações na vida social em decorrência das atividades de cuidado desenvolvidas.

Ocorre que o portador de Alzheimer assume progressivamente um outro modo de ser, embora os traços físicos permaneçam. Boss (1998) nomeou de "perda ambígua” a situação em que o membro da família está fisicamente presente e psicologicamente ausente, como no caso da demência. Este autor explicou que o fenômeno gera conflito, resultando em estresse para todos os membros.

Partindo dessas informações, o presente estudo objetivou investigar as relações intergeracionais diante da doença de Alzheimer. Especificamente, averiguou- 
se na perspectiva de filhas cuidadoras de pais/mães idosos portadores de DA a coesão e a hierarquia entre eles e seus filhos (netos dos portadores). Utilizou-se, como aporte teórico, a perspectiva sistêmica e estrutural da família proposta por Salvador Minuchin (1982).

Nesse contexto, sinaliza-se que este estudo poderá fornecer subsídios teóricos que auxiliarão a compreensão da temática em pauta, assim como fundamentar propostas sociopolíticas, educacionais e sanitárias voltadas para o apoio aos portadores e aos seus familiares. Outrossim, há uma carência de literatura na área. Revisando as bases de dados bibliográficas, tais como os periódicos CAPES e as bibliotecas digitais de teses e dissertações, não foi constatada, no Brasil, nenhuma publicação específica acerca do relacionamento entre o subsistema avós com Alzheimer, suas filhas cuidadoras e seus netos.

\section{Método}

\section{Local do estudo}

A pesquisa foi realizada no Centro de Referência em Assistência à Saúde do Idoso e Portadores da Doença de Alzheimer, que funciona no Centro de Medicina do Idoso (CMI), situado no Hospital Universitário de Brasília (HUB), Distrito Federal.

\section{Participantes}

Participaram do estudo 24 filhas (com idades variando entre 35 e 64 anos) que cuidavam de seus pais/mães idosos (5 pais e 19 mães) com provável/possível diagnóstico da doença de Alzheimer, considerados neste estudo como "avós portadores de DA". A maioria delas estava na meia-idade, era a filha mais velha, casada, tinha nível superior, professava a religiāo católica, era aposentada ou exercia a profissão do lar e possuía nível socioeconômico médio. Também todas eram mães e tinham em média dois filhos, sendo que quatro delas já eram avós e duas eram bisavós.

Como critérios de inclusão, elas deveriam: a) ser filhas da pessoa idosa com provável/possível diagnóstico da DA; b) ser as principais responsáveis pelos cuidados do pai/mãe portador(a) de DA e; c) morar na mesma residência deles. Como critérios de inclusão, os avós com DA deveriam: a) ser atendidos pelo Centro de Referência supracitado; b) ter o diagnóstico de provável/possível doença de Alzheimer e; c) estar no estágio leve ou moderado da enfermidade. A idade dos 
portadores variou entre 70-92 anos de idade, sendo a maioria viúvos e apenas dez casados. Grande parte estava na fase intermediária da doença, possuía ensino básico, professava a religião católica, exercera a profissão do lar antes da doença e convivia diariamente com os netos e, às vezes, com bisnetos. A maior parte dos netos que corresidiam com os idosos se encontrava na fase adulta, seguida da adolescente, sendo poucas as crianças.

\section{INSTRUMENTOS E PROCEDIMENTOS}

A combinação de métodos quantitativos e qualitativos resulta em achados mais significativos para a pesquisa com famílias (Nichols \& Schwartz, 1998). Foram utilizados uma entrevista com roteiro semiestruturado, baseada na revisão bibliográfica, e o Family System Test (FAST). Este foi desenvolvido por Thomas M. Gehring (1993) e está fundamentado na teoria estrutural de Minuchin. Consiste em um processo de investigação quantitativa e qualitativa, destinada a realizar uma análise estrutural e sistêmica das percepçôes dos sujeitos sobre a estrutura de relaçôes familiares, em diversas situações de pesquisa e de prática clínica. As principais dimensões analisadas dizem respeito à coesão e à hierarquia familiar. A representação da família no FAST é apresentada por meio de figuras femininas e masculinas que simbolizam os membros familiares em um tabuleiro monocromático. A posição e distância entre os bonecos no tabuleiro mostram a coesão entre os membros. Simultaneamente, os bonecos são dispostos sobre cilindros de três tamanhos diferentes, representando a hierarquia de cada membro. Todavia, o teste permite identificar não somente um escore geral para toda a família, mas, também, escores específicos para cada subsistema.

Neste estudo será destacado o resultado das representações das tríades avós portadores de Alzheimer-filhas cuidadoras-netos dos portadores nas seguintes situações: antes e após a doença; situação ideal dos relacionamentos e situação de conflito. Ressalta-se que, na revisão bibliográfica, não foram detectadas pesquisas que utilizaram o FAST para avaliar as famílias com membros portadores de DA. Tal fato limitará a discussão deste estudo.

A pesquisa foi aprovada pelo Comitê de Ética em Pesquisa da Faculdade de Medicina da UnB. O levantamento da amostra foi feito através de todos os prontuários dos pacientes que haviam sido atendidos pela equipe profissional do Centro supracitado. Inicialmente, foi feito um contato por telefone informando-se sobre o estudo e solicitando-se a presença no Centro, em data e horário marcados. Ambos os instrumentos foram aplicados individualmente, apenas com as filhas cuidadoras. Após assinatura do Termo de Consentimento Livre e 
Esclarecido, as entrevistas foram gravadas e transcritas. A aplicação do teste e a entrevista duravam, em média, duas horas e cinquenta minutos. As participantes falavam até quando julgavam necessário. Os nomes utilizados neste estudo são fictícios.

\section{FORMA DE ANÁLISE DOS RESULTADOS}

As entrevistas foram analisadas segundo a técnica de Bardin ([1977] 2000) através da pré-análise, exploração do material, tratamento dos resultados, inferência e interpretação. Obedeceu-se às regras de exaustividade, representatividade, homogeneidade, exclusividade e pertinência das categorias temáticas. Os resultados quantitativos do FAST foram analisados através do SPSS WIN/PC 13 (Statistical Package for the Social Sciences - version 13). Os dados foram tratados mediante um conjunto de testes não-paramétricos. Esta opção obedeceu à lógica da natureza dos dados, pois a amostra foi não-aleatória e não apresentou distribuição normal segundo o teste de Kolmogorov-Smirnov.

\section{Resultados}

Inicialmente, apresenta-se a categorização temática resultante da análise de conteúdo. Visando uma melhor compreensão, destaca-se para cada subcategoria um exemplo das falas das participantes. Posteriormente, expressam-se os resultados quantitativos do FAST.

\section{RESULTADOS QUALITATIVOS}

Categoria temática: relaçôes intergeracionais na perspectiva das cuidadoras (RIC): nesta categoria, estão presentes os conteúdos das falas das participantes acerca das relaçôes entre elas, seus pais/mães idosos (avós) portadores de DA e seus filhos (netos). Foi dividida em duas subcategorias: 1) as relaçôes intergeracionais antes da doença e; 2) o impacto da doença de Alzheimer nas relações intergeracionais.

Subcategoria 1: relações intergeracionais antes da doença de Alzheimer (RIADA):

a) relaçôes intergeracionais favoráveis (afetivas) antes da doença (RIFAD): "Antes da doença, mamãe era muita solidária comigo e com os netos dela. E minha filha sempre foi a companheirinha dela pra ir pra missa ou pra qualquer lugar” (Beatriz). 
b) relações intergeracionais desfavoráveis (conflituosas) antes da doença (RIDAD): "Mamãe criou os filhos desunidos. Eu e ela brigávamos porque ela não aceitava a maneira que criava meus filhos. E eles não curtiam o jeito dela" (Diana).

Subcategoria 2: o impacto da doença de Alzheimer nas relaçôes intergeracionais (IDARI):

a) relações intergeracionais favoráveis (afetivas) após a doença (RIFADA): "Se o papai estiver passando mal de madrugada, meu filho levanta e ajuda a cuidar. Ele chega meia-noite da faculdade, mas não bota banca pra ajudar. E ela [filha], todos os dias, faz o almoço e dá o banho na vó, antes de ir ao colégio" (Gabriela).

b) relações intergeracionais desfavoráveis (conflituosas) após a doença (RIDEAD): "Meu filho e meu neto estão enciumados porque estou com a atenção mais voltada para minha mãe. Além disso, ela bateu com uma vassoura no meu neto porque achava que ele tinha roubado ela. Na hora, ficamos indignados. Só depois vimos que era da doença" (Sara).

\section{REsulTADOS QUANTITATIVOS}

1 - Através do FAST, constatou-se que não houve diferença significativa na coesão entre as portadoras de Alzheimer e seus netos/suas netas antes e após o surgimento da DA ( $Z=-1,07$; ns). Contudo, nas representaçôes atuais das relações intergeracionais, a coesão das filhas cuidadoras com os próprios filhos foi significativamente maior do que a coesão destes com suas avós portadoras da DA ( $\mathrm{Z}=-$ $3,38 ; \mathrm{p}<0,001)$.

2 - Comparando-se os resultados das representaçóes de conflitos intergeracionais com as representações ideais, observou-se uma menor coesão entre as portadoras de Alzheimer e seus netos nas situações conflituosas $(Z=-2,60 ; p<0,01)$. Isso implica que, para as cuidadoras, os filhos delas se afastavam dos avós diante dos conflitos, mas, para elas, o ideal era que existisse uma maior coesão entre o subsistema avós-netos.

3 - Nas representações atuais, a coesão das cuidadoras com seus filhos foi tendencialmente maior do que a coesão destes com os avós não portadores da DA $(\mathrm{Z}=-1,8 ; \mathrm{p}<0,10)$.

4 - No que diz respeito à hierarquia, verificou-se que no relacionamento entre as portadoras de Alzheimer e seus netos estes possuíam uma posição hierarquicamente superior em relação àquelas na situação atual $(Z=-2,007 ; \mathrm{p}<0,05)$ e ideal $(Z=-2,18 ; p<0,05)$. 


\section{DisCUSSÃo}

$\mathrm{Na}$ família, os padrões e as regras do sistema são transmitidos de geração a geração. Nesse cenário, os avós exercem um importante papel, mas os relacionamentos destes com os netos podem ser incentivados ou inibidos pelos pais, que atuam como mediadores na relação. No presente estudo, a maioria das participantes afirmou que existia um bom relacionamento intergeracional antes do surgimento da doença de Alzheimer, fator que certamente contribuiu para que elas assumissem o papel de cuidadoras. Dentre outros aspectos, as filhas que revelaram a existência de conflitos antes da doença podem ter assumido essa função como falta de opção ou como oportunidade de rever os erros do passado e resgatar os elos afetivos.

Após o desencadeamento da enfermidade, verificou-se que não houve diferença significativa na coesão entre as portadoras de Alzheimer e seus netos/suas netas. Na pesquisa de Pelisoli, Teodoro e Dell'Aglio (2007) em que foi utilizado o FAST com adolescentes vítimas de abuso sexual infantil, constatou-se que em termos de coesão intergeracional a mãe e as filhas eram mais próximas em todas as situações (atual, ideal e conflito) do que a mãe com o pai, ou com qualquer outro membro da família da mesma geração. No presente estudo, percebeu-se, também, que nas representações atuais a coesão das cuidadoras com seus filhos foi significativamente maior do que a coesão destes com suas avós.

Todavia, averiguou-se que, se comparada com outros netos, a maioria dos filhos das respondentes tinha uma maior proximidade afetiva com os avós portadores de DA e exerciam mais ações de solidariedade e auxílio nos cuidados. Tal dado refletiu a proximidade geográfica, ou seja, pelo fato de residirem na mesma casa em que os avós moravam, bem como a intensidade dos laços afetivos, especialmente por parte das cuidadoras e seus filhos. A título de ilustração, seguem alguns depoimentos:

Sou muito ligada aos meus filhos e eles a mim. Eles me ajudam a cuidar da mamãe. Nenhum filho dos meus irmãos manifestou esse interesse de ajudar a cuidar dela. [...] Ninguém quer ter compromisso! Só meus filhos e eu (Tainá). Eu tenho uma sobrinha que é psicóloga, mas nunca se propôs a me ajudar, a me ensinar, explicar e eu não sei nem se pode. [...] Mas a minha sobrinha não sabe telefonar e perguntar como ela está, nem mesmo a neta que ela criou faz isso. É lamentável (Karina). 
Porém, em poucos casos, o envolvimento de outros membros nessa tarefa também foi sinalizado. Sofia, por exemplo, sinalizou o que se segue:

Ainda bem que tenho o apoio da minha neta. Ela dá banho na minha mãe e diz: "bisavó, vem aqui". Ela põe pra dormir, dá o lanche dela. Ela ajuda muito! Ela é uma criança ainda [...] e faz muito mais pela minha mãe do que a minha filha, que é neta dela. A minha neta senta com a mamãe na sala, conversa e brinca de boneca. E eu acho bonito, porque ela é bisneta, ela já tá numa escala familiar mais longe. Quem deveria cuidar eram as filhas, as netas, e não a bisneta.

Nas relações intergeracionais, o papel de bisavó é considerado o mais importante do ponto de vista simbólico e emocional (Doka \& Mertz, 1988). Os relatos obtidos pelas cuidadoras deste estudo corroboraram a pesquisa de Brody (1989), ao destacar a importância da interlocução entre as gerações, da possibilidade que os mais novos têm de aprender com os mais velhos e de estes serem beneficiados por aqueles, em virtude do apoio prestado diante da doença de Alzheimer. Além disso, ressalta-se que o aumento no número de famílias monoparentais, além de vários membros trabalharem fora do lar, limitou o número de pessoas disponíveis para exercerem as tarefas de cuidado em casa (Biegel \& Schulz, 1999). Tais fatos levam crianças e adolescentes a assistirem ou assumirem os cuidados de adultos com doenças degenerativas que moram na mesma residência (Lackey \& Gates, 2001).

As participantes, além das tarefas de rotina da casa e de cuidarem dos pais portadores, também assistiam os pais não-portadores que, na medida do possível, auxiliavam nos cuidados dos cônjuges. A vivência de estresse, limitações sociais e a sobrecarga de papéis familiares exercida foram mencionadas por elas como um impacto negativo da doença nas relações com os subsistemas da família. Um dado a ser destacado é que, dentre as 24 entrevistadas, 15 declararam que após o surgimento da doença foram acirrados os conflitos entre os avós portadores de Alzheimer e pelo menos um de seus filhos. Em dois casos também foram detectados conflitos entre avós-mães-netos-bisnetos. Segundo Silveira (2003), diante da DA, malgrado haver situações nas quais familiares reatam relações após um período de conflitos - ocasiōes em que a doença tem a função de unir -, é comum que os conflitos se intensifiquem em momentos de crise, desencadeando, por vezes, separações irreversíveis.

De acordo com Féres-Carneiro (1996), numa dinâmica familiar facilitadora do desenvolvimento, os conflitos podem ser apresentados e positivamente valorizados a partir do momento em que se buscam soluções para eles. Isso não implica dizer que todos os conflitos serão resolvidos, pois em qualquer vivência grupal 
eles estarão presentes, em maior ou menor grau de intensidade, podendo ser ou não um aspecto de crescimento para os membros. Além disso, devem ser levados em consideração os padrões de comunicação na família. Para Stierlin (1981), repetidas perturbações na comunicação e nas relações familiares repercutem e sustentam conflitos interpessoais e intrapsíquicos.

Nesta pesquisa, em alguns casos em que os netos tinham uma maior aproximação afetiva com os avós antes da DA, observou-se uma reação de negação à enfermidade e uma maior intensidade nos conflitos diante do processo demencial. A perda gradativa do apoio emocional dos avós pode ter funcionado como catalisador das situações conflituosas. Como exemplos, destacam-se os discursos de Ana e Lívia:

Mamãe e minha filha eram muito apegadas uma à outra. Com um certo tempo, mamãe começou a ter ciúmes dela com meu pai. Ela achava que eles tinham um caso e faziam sexo. [...] Um dia, minha filha teve que ficar trancada pra minha mãe não agredi-la [chora...]. [...] Atualmente, com os meus filhos ocorre o seguinte: cada um se tranca no seu quarto, pra não responder pra vó, pra não magoá-la, pra evitar esses aborrecimentos (Ana).

A gente não tinha problemas, até o dia em que eu trouxe mamãe pra morar conosco. Alterou a vida de todos. Ela começou a dizer que meu filho conversava com os amigos no telefone tramando matá-la. Falava coisas duras com ele e ele chorava. Às vezes, ele me perguntava: "mãe, por que a vó fala isso comigo? Logo eu! Por que eu?”. Ele é afilhado dela e muito ligado a ela antes da doença. Eu dizia: “sua avó não está boa, ela não sabe o que faz!". [...] Ele não queria aceitar que ela estava doente. [...] Começou a dar problemas pra gente... arranjou uma namorada, saiu de casa e teve um filho com ela (Lívia).

É fundamental compreender a família, atentando para o momento do ciclo de vida em que se encontra. Como um sistema, ela depende de padróes transacionais, da acessibilidade de padróes transacionais alternativos e da flexibilidade para mobilizá-los em determinadas situações (Minuchin, 1982). São comuns as coalizóes entre os membros. A coalizão é uma propriedade das tríades (ex.: avó, mãe e filho) e diz respeito à aliança de duas pessoas ou unidades sociais contra uma terceira. Aliado a esse aspecto, é crucial avaliar as forças centripetas e centrifugas que atuam no sistema familiar (Stierlin, 1979). A primeira faz com que o sujeito fique cada vez mais próximo ao núcleo familiar e a segunda impele o indivíduo a sair do sistema, a se distanciar do centro.

A pressão e a vivência de conflitos envolvendo os familiares e os portadores de Alzheimer podem favorecer a atuação de forças centrífugas. Movidos pela pressão, muitos saem de casa para não terem que lidar com as demandas advindas da 
demência. Para Bowen (1978), “a pessoa que foge do lar está tão emocionalmente ligada a ele quanto aquela que lá permanece e se utiliza de mecanismos interiores para controlar essa ligação. [...] Foge, mentindo para si mesmo que o que faz tem como objetivo o alcance de sua independência" (Bowen, 1978: 535).

Segundo Nichols e Schwartz (1998), o grau de intensidade dos problemas está ligado ao grau de indiferenciação, à extensão do rompimento emocional com as famílias de origem do casal e ao nível de estresse no sistema. Nesta pesquisa, foi visto que para as entrevistadas os filhos delas se afastavam dos avós diante dos conflitos, mas o ideal era que existisse uma maior coesão entre a díade avós-netos. Essa idealização estava arraigada aos valores, às crenças e aos mitos das famílias, especialmente ao da união. Os mitos familiares garantem a estabilidade de coesão, proporcionando explicações racionalizadas para os comportamentos dos indivíduos na família, bem como ocultando as motivaçōes e os aspectos irracionais que os dirigem. Enquanto um mito funcionar dessa maneira, ele deve ser o sistema de explicação operante e não poderá ser objeto de nenhuma metacomunicação; não poderá receber nenhum comentário ou crítica, quer seja de um familiar ou de uma pessoa externa (Miermont, 1994).

Outro dado importante a ser discutido refere-se à mudança hierárquica dos avós em relação aos netos após a doença de Alzheimer. O alto poder assumido por estes propiciou mudanças de atitudes e valores que afetaram o sistema familiar. Como ilustração, apresenta-se o discurso de Carolina:

Meu filho adolescente gosta muito da avó, e foi uma desilusão para ele saber que ela está com Alzheimer. A família se desestrutura porque, de repente, tudo gira em torno de quem está doente. Depois da doença, passei a ter problemas sérios com ele, porque agora, além dele usar drogas, roubou um carro junto com os colegas e planejava assaltar um banco. Tive que ir pra delegacia. [...] Se você tem uma pessoa em casa que ama e já não pode conversar com ela, sofre uma desilusão. Acho que o uso de drogas dele tem a ver com essa desilusão. Ele vira as costas pra mim, não quer me ouvir. E cuidando da mamãe acabei deixando o meu filho um pouquinho de lado. Ele não era assim. Sempre foi o xodó dela. Sabe como é avó, né? Faz tudo! $\mathrm{E}$ isso, às vezes, me tirava um pouco a autoridade, porque ela sempre quis mandar e mandava nele antes da doença. Ela foi o referencial de poder para ele (Carolina).

Beavers e Hampson (1995) afirmaram ser fundamental valorizar e compreender a estrutura hierárquica dos sistemas de interação internos e periféricos da família, os quais incluem os de ordem maior, como a família extensa e as redes sociais mais amplas. Conforme Clingempeel, Colyar, Brand e Hetherington (1992), 
a fase púbere dos netos é um dos períodos de transições que mais podem afetar o relacionamento pais-avós, envolvendo o sistema social. No caso acima apresentado, observou-se que a perda do referencial hierárquico que a avó exercia em relação ao neto adolescente pode ter mobilizado, juntamente com outras questóes inerentes a essa etapa da vida, a eclosão de atos infracionais por parte deste.

Ressalta-se que o envolvimento de netos dos portadores da DA com drogas ilícitas foi observado em cinco famílias deste estudo, sendo que em três delas tais comportamentos foram manifestados logo após o surgimento da demência dos avós. Outros atos de infração cometidos por netos, após o surgimento da enfermidade destas figuras, também foram observados em outros três casos. Segundo Minuchin (1982):

Os sintomas podem constituir uma expressão de uma disfunção familiar. $\mathrm{Ou}$ podem ter surgido no membro individual da família em razão de circunstâncias de sua vida particular e, então, terem sido apoiados pelo sistema familiar. Em qualquer caso, o consenso familiar de que um membro é o problema indica que, em algum nível, o sintoma está sendo reforçado pelo sistema (Minuchin, 1982: 108).

Os sintomas da demência podem gerar afastamento e estigmas sobre os pacientes, favorecendo o isolamento do seu contexto sociofamiliar. Outrossim, muitas crises de agitação ou, contrariamente, a apatia, podem ser consequências da influência do ambiente em que os portadores estão inseridos. Segundo Caldas (1998), é importante manter o paciente em ambientes conhecidos, como forma de respeitar as lembranças de vida que ainda lhe restam e evitar que se desoriente em lugares estranhos. Entrementes, nem sempre é possível fazer com que o idoso permaneça em sua morada. Na maioria dos casos deste estudo, devido ao tratamento ou por falta de condições de morarem sozinhos, os pacientes tiveram que sair de suas casas para residirem com as filhas, alterando as rotinas familiares e as relaçôes intergeracionais.

\section{CONSIDERAÇÕES FINAIS}

A posição ocupada pelos avós na família pode ser central ou periférica e envolve questôes de autoridade, poder, tradição e relações entre as geraçôes ao longo dos tempos. A corresidência com os avós idosos pode ser uma estratégia familiar utilizada para beneficiar as gerações nos aspectos psicológicos, sociais e econômicos. Todavia, diante de algumas situações tais como a doença de Alzheimer, 
ela apresenta mudanças dos papéis e do intercâmbio entre pais-filhos-netos-bisnetos e até tataranetos. A homeostase familiar, para ser atingida, necessita de reavaliaçōes e adaptações diárias. As famílias vão, aos poucos, modificando suas regras de funcionamento, buscando se auto-organizar diante dos desafios que a doença impõe. Ocorre que, por vezes, os cuidadores, os portadores e seus familiares não dispõem de uma instituição que possa acolhê-los, escutá-los e dissipar várias dúvidas acerca da $\mathrm{DA}$, o que favoreceria o crescimento mútuo entre os membros. O Centro de Referência em Assistência à Saúde do Idoso e Portadores da Doença de Alzheimer do HUB oferece essa possibilidade. Todavia, nem todas as cidades brasileiras dispõem dessa assistência.

Outrossim, a vergonha e a evitação do convívio social mais amplo é comumente relatado pelas pessoas que cuidam de idosos com DA. Quanto mais avançado é o estágio da demência, mais difíceis ficam as possibilidades de saída de casa para desenvolver atividades sociais. Como, muitas vezes, as cuidadoras não têm com quem deixar os seus genitores, acabam também tendo sua vida social limitada, o que afeta a relação com os membros da família nuclear e extensa e sua própria saúde. Propõese que não apenas as pessoas cuidadoras, mas também os membros da família extensa participem de grupos de apoio que esclareçam a doença, busquem facilitar a comunicação intergeracional, sinalizem o autocuidado, a divisão de tarefas entre os membros e maneiras de lidar com as mudanças advindas com a demência, levandose em consideração a estrutura e a dinâmica própria de cada família.

Além disso, a terapia familiar é fundamental em diversas situações. Conforme Eisdorfer, Czaja e Lowenstein (2003) apontam, os modelos de intervenção sistêmica junto às famílias com portadores de DA destacam os cuidadores primários e encorajam os membros a negociarem as diferentes responsabilidades, ressaltando que o recurso está no sistema familiar. A teoria estrutural (Minuchin, 1982), por exemplo, indica que o terapeuta numa posição de liderança una-se à família, investigue e avalie sua estrutura subjacente e crie circunstâncias que permitam a transformação no sistema como um todo. Para futuras pesquisas, recomenda-se investigar o impacto da doença de Alzheimer nas relações conjugais e no sistema extrafamiliar.

\section{REFERÊNCIAS BIBLIOGRÁFICAS}

Bardin, L. (1977/2000). Análise de conteúdo. Lisboa: Edições 70.

Beach, D. L. (1994). Family care of Alzheimer victims: an analysis of the adolescent experience. The American Journal of Alzheimer's Care and Related Disorders and Research, v. $9,12-19$. 
. (1997). Family caregiving: the positive impact on adolescent relationships. Gerontologist, v. 37, no 2, 233-238.

Beavers, W. R. \& Hampson, R. B. (1995). Familias exitosas: evaluación, tratamiento e intervención. Barcelona: Paidós.

Biegel, D. E. \& Schulz, R. (1999). Caregiving and caregiver interventions in aging and mental illness. Family Relations, v. 48, 345-354.

Boss, P. (1998). A perda ambígua. Em Walsh, F. \& McGoldrick, M. (orgs.). Morte na familia: sobrevivendo às perdas (pp. 187-198). Porto Alegre: Artes Médicas.

Bowen, M. (1978). Family therapy in clinical practice. New York: Jason Aronson.

Brody, E. M. (1989). The family at risk. Em Light, E. \& Lebowitz, B. D. (eds.). Alzheimer's disease treatment and family stress: directions for research (pp. 2-49). Washington, DC: National Institute of Mental Health.

Caldas, C. P. (1998). Cuidados com o paciente portador de demência. Em Caldas, C. P. (org.). Saúde do idoso: a arte de cuidar (pp. 139-141). Rio de Janeiro: Ed. UERJ.

Clingempeel, W. G.; Colyar, J. J.; Brand, E. \& Hetherington, E. M. (1992). Children's relationships with maternal grandparents: a longitudinal study of family structure and pubertal status effects. Child Development, v. 63, 1404-1422.

Creasey, G. L., \& Jarvis, P. A. (1989). Grandparents with Alzheimer's disease: effect of parental burden on grandchildren. Family Therapy, v. 16, 79-85.

Doka, K. J. \& Mertz, M. E. (1988). The meaning and significance of greatgrandparenthood. The Gerontologist, v. 28, no 2, 192-197.

Eisdorfer, C.; Czaja, S. J. \& Lowenstein, D. A. (2003). The effect of a family therapy and technology-based intervention on caregiver depression. The Gerontologist, v. 43, no 4, 521-531.

Féres-Carneiro, T. (1996). Família: diagnóstico e terapia. Petrópolis: Vozes.

Gehring, T. M. (1993). Family system test (FAST). Germany: Hogrefe \& Huber publishers.

Goldani, A. M. (1999). Mulheres e envelhecimento: desafios para os novos contratos intergeracionais e de gêneros. Em Camarano, A. A. (org.). Muito além dos 60: os novos idosos brasileiros (pp. 75-114). Rio de Janeiro: IPEA.

Haley, J. (1976). Problem-solving therapy: new strategies for effective family therapy. San Francisco: Jossey-Bass.

Kelsey-Smith, M. \& Beavers, R. W. (1981). Family assessment: centripetal and centrifugal family systems. The American Journal of Family Therapy, v. 9, 3-12.

Lackey, N. R. \& Gates, M. F. (2001). Adults' recollections of their experiences as young caregivers of family members with chronic physical illnesses. Journal of Advanced Nursing, v. 34, no 3, 320-328.

Laws, S. M.; Hone, E.; Gandy, S. \& Martins, R. N. (2003). Expanding the association between the APOE gene and the risk of Alzheimer's disease: possible roles for APOE 
promoter polymorphisms and alterations in APOE transcription. Journal of Neurochemistry, v. 84, 1215-1236.

Mayer, M. (2001). Chronic Sorrow in caregiving spouses of patients with Alzheimer's disease. Journal of Aging and Identity, v. 6, no 1, 49-60.

Miermont, J. (1994). Dicionário de terapias familiares: teoria e prática. Porto Alegre: Artes Médicas.

Minuchin, S. (1982). Famílias, funcionamento e tratamento. Porto Alegre: Artes Médicas.

Nichols, M. P. \& Schwartz, R. C. (1998). Terapia familiar: conceitos e métodos. Porto Alegre: Artes Médicas.

Olson, D. H.; Russel, C. S. \& Sprenkle, D. H. (1983). Circumplex model of marital and family systems: IV. Theoretical update. Family Process, v. 22, 69-83.

Organização Mundial de Saúde - OMS (1994). Ayuda para cuidadores de personas con demencia. Department of Social Change and Mental Health. Genebra: OMS.

Pelisoli, C.; Teodoro, M. L. M. \& Dell'Aglio, D. D. (2007). A percepção de família em vítimas de abuso sexual intrafamiliar: estudo de caso. Arquivos Brasileiros de Psicologia, v. 59, no 2, 256-269.

Penna, T. (2004). Dinâmica psicossocial de famílias de pacientes com câncer. Em Filho, J. M. \& Burd, M. (orgs.). Doença e família (pp. 379-389). São Paulo: Casa do Psicólogo. Sawatzky, J. E. \& Fowler-Kerry, S. (2003). Impact of caregiving: listening to the voice of informal caregivers. Journal of Psychiatric and Mental Health Nursing, v. 10, 277-286.

Silveira, T. M. (2003). "Fomos escolhidos": um estudo sobre cuidadores familiares principais. Tese de Doutorado, Pontifícia Universidade Católica do Rio de Janeiro, Rio de Janeiro.

Stierlin, H. (1979). Psicoanálisis y terapia de família. Espanha: Icaria editorial. . (1981). Separating parents and adolescents. New York: Jason Aronson.

Szinovacz, M. E. (2003). Caring for a demented relative at home: effects on parentadolescent relationships and family dynamics. Journal of Aging Studies, v. 17, 445-472.

Wood, B. (1985). Proximity and hierarchy: orthogonal dimensions of family interconnectedness. Family Process, v. 24, no 4, 497-507.

\section{Notas}

1 Agradecemos o apoio financeiro da CAPES.

Recebido em 26 de novembro de 2007 Aceito para publicação em 29 de fevereiro de 2008 